\title{
BIBLIOGRAFÍA ITALIANA DE TEMÁTICA ARABE (II)
}

Por

MARIA MAGDALENA MARTÍNEZ ALMIRA

Con este título deseo presentar dos trabajos de investigación realizados y publicados en Italia, ejemplares que constituyen una seria ayuda para el mejor conocimiento del mundo musulmán. Las obras en cuestión son dos, si bien una de ellas esta publicada en dos volúmenes, me refiero aquí a los estudios publicados en honor del Profesor Roberto Rubinacci que más adelante presentaré.

A modo de introducción he de decir que en ningún caso se trata de obras de investigación o estudios interconexos, puesto que el primer texto, Fonti e Studi italiani per la storia dell-Africa está inserto en un proyecto de investigación constituido en el año 1982; mientras que el segundo trabajo, Studi arabo-islamici in onore di Roberto Rubinacci nel suo settantesimo compleanno tiene como su mismo título indica, una finalidad muy concreta: el homenaje por su cumpleaños a Roberto Rubinacci.

El libro titulado Fonti e studi italiani per la storia dell'Africa es el volúmen Il de la obra que bajo el mismo epígrafe presenté en el número anterior de la revista "Sharq Al-Andalus» (1). La obra a cargo del Profesor Federico Cresti ofrece reseñas sobre una serie de documentos del Magreb que comprenden desde el siglo XVII hasta el XIX. La presentación ha sido efectuada por el Profesor Salvatore Bono, artífice en gran medida de la constitución de este proyecto investigador que integra a numerosos "africanistas" italianos. Los documentos, publicados por la Universidad de Estudios-Departamento de Ciencia Histórica de Perugia en 1988, están concebidos en dos grandes bloques: el primero de ellos comprende 22 volúmenes procedentes del Archivo Stori-

(1) Al respecto, consultar la «Bibliografía italiana de temática árabe», en "Sharq Al-Andalus». Estudios Arabes, ${ }^{\circ}{ }^{\circ} 4,1987$ donde se presente el primer volumen de la serie citada. 
co della Sacra Congregazione per l'Evangelizzazione dei Popoli (già «De Propaganda Fide»), bajo la serie "Scritture Riferite nei Congressi» y que abarca la zona geográfica conocida como "Barbaria", la cual incluye a todos los países de Africa del Norte excepto Egipto. Estos documentos se fechan entre 1.638 y 1.892 y constituyen un instrumento de primera mano para conocer las relaciones político-religiosas entre los países del Magreb y España.

El segundo bloque comprende el volúmen 25 de estos documentos catalogados por el mismo Archivo histórico y recogidos en la serie "Fondo di Vienna». Abarcan un período inferior a 20 años, concretamente desde 1738 hasta 1791, con idéntica temática al anterior. Si bien, en nuestro caso, apenas hay referencias a correspondencia entre las altas jerarquías eclesiasticas españolas y países norteafricanos como puedan ser Argelia o Túnez, debido ello, al cambio en la política hispano-magrebí.

Entre los innumerables documentos recogidos en este volúmen, destacaría aquéllos que hacen mención a la administración de los Hospitales de Túnez y Argelia, las instrucciones por parte del arzobispado español, para el buen funcionamiento de las misiones a cargo de distintas órdenes monacales, los nombramientos y cesiones de los altos cargos representativosmisionales y las expresiones de gratitud ante ciertos envíos monetarios destinados al ejercicio de la caridad entre los pobres en períodos navideños. Testimonios de la actividad misionera de España (así como de los países europeos que ejercian algún tipo de colonialismo o dominio sobre estados norteafricanos) durante el período subsiguiente a la expulsión de los moriscos.

Con un planteamiento totalmente distinto se presentan los dos volúmenes que componen los «Studi arabo-islamici i onore di Roberto Rubinacci nel suo settantesimo compleanno", publicados por el Instituto Universitario Orientale de Nápoles en 1985 a cargo de Clelia Sarnelli Cerqua. Los autores de estos trabajos de investigación, profesores docentes de la "Scuola di Studi Islamicin, han participado en el homenaje al arabista-islamólogo Roberto Rubinacci, artífice de la nueva configuración del «Instituto Universitario Orientale» de Nápoles.

Comprende la obra 50 trabajos de investigación que versan sobre aspectos históricos, políticos, religiosos, jurídicos, filosóficos, sociales y literarios; todos ellos presentados por Clelia Sarnelli y con una dedicación a cargo del profesor Francesco Gabrieli al Profesor homenajeado.

El elevado grado científico de esta obra no permite destacar aspectos o estudios determinados, puesto que iría en detrimento de aquéllos no mencionados. Hay que dejar constancia de la variedad de los temas cuestionados, de la riqueza del material que se menciona como Fuentes consultadas y como no, de la personalidad investigadora de los estudiosos que han colaborado en su publicación.

Ateniéndome a los objetivos de la revista "Sharq Al-Andalus" menciona- 
ré dos de los artículos recogidos en el segundo volúmen de la obra presentada. El primero de ellos esta firmado por María Teresa Mascari quien efectúa un estudio titulado "Brevi note sulla poesía di Ibn "Amar al-Andalusi», el mismo nos presenta al escritor Ibn "Amar, perteneciente a la España musulmana del siglo XI, poeta cuya vida literaria estuvo ligada a la corte de al-Mu ctadid quien en 1053 lo nombra poeta oficial de la anterior. El segundo artículo es obra de Clelia Sarnelli la cual bajo el título "Al-Hagari a Rouen e a Parigi» recoge la traducción del Kìtab Nāṣir al-dīn, capítulos IV y V, libro escrito por un autor hispano marroquí conteniendo la descripción de la llegada del mismo a Francia así como los sucesos que le acontecen. 